\title{
Fluid Ounce British
}

National Cancer Institute

\section{Source}

National Cancer Institute. Fluid Ounce British. NCI Thesaurus. Code C48577.

A traditional unit of liquid volume equal in the British Imperial system to 1/20 pint, or 1.733871 cubic inches or 28.413063 milliliters. 